\title{
Interação entre salinidade e fósforo na cultura do rabanete ${ }^{1}$
}

\author{
Phosphorus-salinity interaction in radish
}

\author{
Francisco Ronaldo Alves de Oliveira ${ }^{2}$, Francisco de Assis de Oliveira ${ }^{3 *}$, José Francismar de Medeiros², Valdívia \\ de Fátima Lima de Sousa² e Alcione Guimarães Freire ${ }^{2}$
}

\begin{abstract}
Resumo - O uso de água salina, na irrigação, tem sido um desafio para os pesquisadores e produtores rurais, sendo constantemente desenvolvidos estudos que possibilitem o uso de água, de qualidade inferior, sem afetar o rendimento e qualidade dos produtos agrícolas. Este trabalho foi realizado com o objetivo de avaliar o efeito de diferentes níveis de salinidade da água de irrigação e doses de fósforo na cultura do rabanete. O delineamento experimental adotado foi inteiramente ao acaso, arranjados em esquema fatorial 4 × 4 com três repetições. Os tratamentos resultaram da combinação de quatro níveis de salinidade da água de irrigação $\left(\mathrm{S}_{1}-0,5 ; \mathrm{S}_{2}-2,0 ; \mathrm{S}_{3}-3,5\right.$ e $\left.\mathrm{S}_{4}-5,0 \mathrm{dS} \mathrm{m}^{-1}\right)$ com quatro doses de fósforo $\left(0 ; 100 ; 200 \mathrm{e} 300 \mathrm{mg} \mathrm{dm}^{-3}\right)$. As variáveis avaliadas foram: número de folhas, área foliar, massa fresca e seca das raízes. A cultura do rabanete respondeu significativamente a interação entre salinidade e fósforo para área foliar, massa fresca e seca das raízes; e de forma isolada para número de folhas. Doses crescentes de fósforo reduziram à sensibilidade da cultura do rabanete à salinidade de até $3,5 \mathrm{dS} \mathrm{m}^{-1}$. O manejo da adubação fosfatada é uma alternativa para amenizar o efeito da salinidade no desenvolvimento da cultura do rabanete.
\end{abstract}

Palavras-chave - Raphanus sativus L.. Salinização. Plantas-efeito do fósforo.

\begin{abstract}
The use of saline water for irrigation has been a challenge for the researchers and farmers, studies continually being developed to enable the use of lower quality water without interfering with the yield and quality of products. This work was conducted to evaluate the effect of different salinity levels water irrigation and phosphorus doses in radish. It was used an entirely statistical randomized design, in factorial scheme $4 \mathrm{x} 4$, with three replications. The treatments resulted from the combination of four salinity levels of irrigation water $\left(\mathrm{S}_{1}-0.5 ; \mathrm{S}_{2}-2.0 ; \mathrm{S}_{3}-3.5\right.$ and $\left.\mathrm{S}_{4}-5.0 \mathrm{dS} \mathrm{m}^{-1}\right)$ with four phosphorus levels $\left(0 ; 100 ; 200\right.$ and $\left.300 \mathrm{mg} \mathrm{dm}^{-3}\right)$. The variables evaluated were: number of leaves, leaf area, root fresh and dry weight of roots. The radish responded significantly the interaction between salinity and phosphorus for leaf area, fresh and dry weight of roots, and isolated the factors for number of leaves. Increasing doses of phosphorus reduced the sensitivity of radish culture to salinity up to $3,5 \mathrm{dS} \mathrm{m}^{-1}$. The management of phosphorus is an alternative to alleviate the effect of salinity in the development of radish.
\end{abstract}

Key words - Raphanus sativus L.. Salinization. Plants-effects to phosphorus.

\footnotetext{
* Autor para correspondência

${ }^{1}$ Recebido para publicação em 07/09/2009; aprovado em 07/11/2010

Trabalho desenvolvido com apoio do CNPq - Bolsa IC e convênio FRUTERN-FINEP/UFERSA/FGD

${ }^{2}$ Departamento de Ciências Ambientais e Tecnológicas, UFERSA, Mossoró-RN, Brasil, 59.625-900, ronaldoindep@yahoo.com.br, jfrancismar.rn@ uol.com.br, valdivia_sousa@hotmail.com, alcionegf@hotmail.com

${ }^{3}$ Programa de Pós-Graduação em Irrigação e Drenagem, Departamento de Engenharia de Biossistemas, ESALQ, Piracicaba-SP, Brasil; 13.418-900, thikaoamigao@bol.com.br
} 


\section{Introdução}

O Rabanete (Raphanus Sativus L.) pertence à família das Brassicaceaes e é originária da região mediterrânea. A sua raiz apresenta-se como um bulbo comestível, de cor vermelha e sabor picante. Apresenta propriedades medicinais, como expectorante natural e estimulante do sistema digestivo, contendo vitaminas A, B1, B2, potássio, cálcio, fósforo e enxofre (MINAMI; NETTO, 1997).

As cultivares de maior aceitação produzem raízes globulares, de coloração escarlate brilhante e polpa branca. Atualmente, vem ganhando destaque entre os olericultores, principalmente, por apresentar características atraentes, como ciclo curto e rusticidade, sendo a colheita realizada de 25 a 35 dias após a semeadura (FILGUEIRA, 2008).

Por ser uma cultura produzida principalmente por pequenos e médios olericultores, localizados nos cinturões verdes das grandes cidades, o rabanete é irrigado com água oriunda de fontes superficiais, sendo utilizado, em alguns casos, água de qualidade inferior, principalmente, devido ao alto teor de sais dissolvidos.

Diante desta problemática, uma série de pesquisas tem sido desenvolvida objetivando estratégias de manejo da cultura que possibilite o uso de água salina na irrigação das plantas, sem que afete negativamente a produção nem a qualidade dos produtos (ASSIS JÚNIOR et al., 2007; LACERDA et al., 2006; SILVA et al., 2008).

Alguns estudos têm sido desenvolvidos para avaliar a influência da adubação fosfatada em plantas cultivadas em condições salinas. Cerda et al. (1977) avaliaram o desenvolvimento e a produção de gergelim, cultivado em solução nutritiva com diferentes salinidades e níveis de fósforo, e verificaram que a tolerância da cultura a salinidade foi reduzida com aumento do fósforo. No entanto, Lacerda et al. (2006) avaliaram o desenvolvimento de sorgo forrageiro, submetido a concentrações de fósforo em diferentes níveis de salinidade da solução nutritiva, constatando a existência de interação entre salinidade e fósforo sobre o desenvolvimento e nutrição das plantas, esses autores verificaram ainda que os teores de $\mathrm{P}$ no tecido foliar aumentaram em resposta ao aumento de $\mathrm{P}$ na solução, independente do nível de salinidade.

De acordo com Shibli et al. (2001), o aumento de doses de $\mathrm{P}$ pode minimizar os efeitos adversos da salinidade sobre o desenvolvimento das plantas. Assim, uma adequada nutrição fosfatada é de fundamental importância, em plantas cultivadas sob condições de estresse salino. No entanto, segundo Grattan e Grieve (1999), a interação entre salinidade e nutrição fosfatada em plantas é bastante complexa e dependente da espécie vegetal ou cultivar, estádio de desenvolvimento, composição e concentração, além da concentração de $\mathrm{P}$ no meio de cultivo.
Segundo Marschner (2002), a deficiência de fósforo proporciona redução da área foliar, através da limitação do número e da expansão foliar, sendo afetada também pela deficiência hídrica, associada à redução da condutividade hidráulica do sistema radicular. De acordo com Narloch et al. (2002), a cultura do rabanete, mesmo não sendo muito exigente em nutrientes, responde a adubação mineral, principalmente aos fosfatados.

$\mathrm{Na}$ literatura, são escassos estudos sobre os efeitos da salinidade na cultura do rabanete (JAMIL et al., 2007), principalmente nas condições brasileiras, sendo encontrados poucos, e realizados em condições hidropônicas (BACARIN et al., 2007). A cultura do rabanete é classificada como moderadamente sensível à salinidade, apresentando salinidade limiar de $1,2 \mathrm{dS} \mathrm{m}^{-1}$, para extrato de saturação, e $0,8 \mathrm{dS} \mathrm{m}^{-1}$, para água da irrigação (MAAS; HOFFMAN, 1977). Diante do exposto, este trabalho foi desenvolvido com o objetivo de avaliar a interação de condutividade elétrica da água de irrigação e doses de fósforo na cultura do rabanete.

\section{Material e métodos}

O experimento foi conduzido no período de fevereiro a março de 2009, em casa de vegetação, do Departamento de Ciências Vegetais da Universidade Federal Rural do Semi-Árido (UFERSA), localizado no município de Mossoró, RN, conforme as coordenadas geográficas de $5^{\circ} 11^{\prime} 31^{\prime \prime}$ de latitude sul e $37^{\circ} 20^{\prime} 40^{\prime \prime}$ de longitude oeste de Greenwich, e com altitude média de $18 \mathrm{~m}$.

A estruturadacasadevegetaçãoédeaçogalvanizado, sendo as partes laterais e frontais confeccionadas com tela negra com $50 \%$ de sombreamento. A cobertura é em arco tipo túnel, medindo 7,0 $\mathrm{m}$ de largura e 18,0 m de comprimento, com manta de polietileno de baixa densidade, transparente, com $0,15 \mathrm{~mm}$ de espessura.

$\mathrm{O}$ delineamento experimental utilizado foi $\mathrm{o}$ inteiramente casualizado, arranjados em esquema fatorial 4 x 4, com três repetições, sendo a unidade experimental representada por um vaso com capacidade para $10 \mathrm{dm}^{3}$, contendo três planta em cada vaso. Os tratamentos resultaram da combinação de quatro níveis de salinidade da água de irrigação $\left(\mathrm{S}_{1}-0,5 ; \mathrm{S}_{2}-2,0 ; \mathrm{S}_{3}-3,5\right.$ e $\left.\mathrm{S}_{4}-5,0 \mathrm{dS} \mathrm{m}^{-1}\right)$ com quatro doses de fósforo $\left(\mathrm{P}_{1}-0, \mathrm{P}_{2}-100, \mathrm{p}_{3}-200\right.$ e $\left.\mathrm{P}_{4}-300 \mathrm{mg} \mathrm{dm} \mathrm{dm}^{-3}\right)$. A escolha desses níveis de salinidade deve-se às condutividades elétricas apresentadas pelas águas disponíveis para irrigação, na região onde foi feito o experimento (MEDEIROS et al., 2003; OLIVEIRA; MAIA et al., 1998).

Os diferentes níveis salinos foram obtidos pela dissolução de cloreto de sódio $(\mathrm{NaCl})$, em água proveniente do sistema de abastecimento do campus da UFERSA 
$\left(\mathrm{S}_{1}\right)$, ajustando-se com condutivímetro de bancada, com correção automática a temperatura. A água utilizada apresentou as seguintes características químicas: $\mathrm{pH}=8,30$; $\mathrm{CE}=0,50 \mathrm{dS} \mathrm{m}^{-1} ; \mathrm{Ca}^{2+}=3,10 ; \mathrm{Mg}^{2+}=1,10 ; \mathrm{K}^{+}=0,30 ; \mathrm{Na}^{+}=2,30 ;$ $\mathrm{Cl}^{-}=1,80 ; \mathrm{HCO}_{3}^{-}=3,00 ; \mathrm{CO}_{3}{ }^{2--}=0,20\left(\mathrm{mmol}_{\mathrm{c}} \mathrm{L}^{-1}\right)$.

Foi utilizado um Latossolo Vermelho Amarelo de textura arenosa, coletado na camada de 0-30 m de profundidade, em área não cultivada, localizada no Campus da UFERSA. Uma subamostra foi retirada, seca ao ar, peneirada em malha de $2 \mathrm{~mm}$, e submetida a análises físico-químicas (EMBRAPA, 1997), cujos resultados são apresentadas na Tabela 1 .

O solo foi peneirado em malha de $2 \mathrm{~mm} \mathrm{e}$ acondicionado em vasos plásticos com capacidade para $10 \mathrm{dm}^{3}$, deixando-se cerca de $2 \mathrm{~cm}$ entre a superfície do solo e a borda superior do vaso para facilitar a irrigação, sendo acondicionado de forma a apresentar uma densidade semelhante àquela obtida na análise física.

As diferentes doses de fósforo (fosfato monoamônico), juntamente com o nitrogênio (fosfato monoamônico e uréia) e o potássio (cloreto de potássio), na dose de $100 \mathrm{mg} \mathrm{dm}^{-3}$ de $\mathrm{N}$ e de $\mathrm{K}$, foram aplicadas após o acondicionamento do material de solo nos vasos, sendo os fertilizantes diluídos em água e aplicando-se em cada vaso o volume suficiente para elevar o teor de água do solo até a umidade próxima a máxima capacidade de retenção de água do solo.

O plantio foi realizado através de semeadura direta, utilizando sementes de rabanete (Raphanus sativus L.), cultivar Crimson Giant, colocando-se 12 sementes em cada vaso, distribuídas em três covas a uma profundidade de $2 \mathrm{~cm}$. Aos nove dias após a semeadura, realizou-se o desbaste, deixando três plantas em cada vaso, ficando estas plantas equidistantes entre si, aproximadamente, $10 \mathrm{~cm}$, em espaçamento triangular.

Essa cultivar foi escolhida por ser uma das mais cultivadas no Brasil, produz raízes arredondadas, coloração vermelha intensa, polpa muito branca e firme, com diâmetro variando de $3-4 \mathrm{~cm}$.
A irrigação entre a semeadura e o desbaste foi realizada utilizando-se água proveniente do sistema de abastecimento do campus da UFERSA $\left(\mathrm{S}_{1}\right)$. Após o desbaste, a irrigação foi realizada utilizando água com diferentes níveis salinos, de acordo com os tratamentos aplicados.

As irrigações foram realizadas com a frequência de uma irrigação por dia até os 15 dias após a semeadura (DAS), enquanto que do $16^{\circ}$ DAS até a colheita foi adotada a frequência de duas aplicações por dia (uma pela manhã e outra pela tarde). Em cada irrigação, foi aplicado um volume de água suficiente para elevar a umidade do solo próximo da máxima capacidade de retenção de água no solo. $\mathrm{O}$ volume de água aplicado em cada vaso foi determinado através de pesagens diárias.

A colheita foi realizada 35 dias após a semeadura, sendo que as plantas de cada unidade experimental foram colhidas separadamente e acondicionadas em sacolas plásticas previamente identificadas, em seguidas foram transportadas para o Laboratório de Irrigação e Salinidade do Departamento de Ciências Ambientais da UFERSA.

Para o número de folhas (NF), foram consideradas apenas aquelas que apresentavam mais de $70 \%$ de sua área com coloração verde. Para determinação da área foliar (AF), foi utilizado o integrador de área foliar, modelo LI-3100 da Licor. O tubérculo de cada planta foi limpo logo após a colheita, utilizando um pano, em seguida o tubérculo foi separado da raiz e, em balança de precisão $(0,01 \mathrm{~g})$, determinando-se a massa fresca da raiz (MFR). Para determinação da massa seca da raiz (MSR), as plantas foram acondicionadas em sacos de papel e postas para secar em estufa de circulação forçada, à temperatura de $70{ }^{\circ} \mathrm{C} \pm 1{ }^{\circ} \mathrm{C}$, até atingir peso constante.

Foi realizada uma avaliação, no final do ciclo da cultura, sendo considerado em cada parcela o valor médio das três plantas de cada de cada vaso. Os resultados obtidos foram submetidos a análises de variância e de regressão, e, de acordo com o nível de significância no teste $\mathrm{F}$ para os níveis de salinidade e doses de fósforo, procedeu-se analise de regressão polinomial, utilizando-se o nível de

Tabela 1 - Características físicas e químicas do solo utilizado no experimento

\begin{tabular}{|c|c|c|c|c|c|c|c|c|}
\hline $\mathrm{pH}$ & M.O. & $\mathrm{P} *$ & $\mathrm{~K}$ & $\mathrm{Na}$ & $\mathrm{Ca}$ & $\mathrm{Mg}$ & $\mathrm{Al}$ & $\mathrm{H}$ \\
\hline & $(\%)$ & $\left(\mathrm{mg} \mathrm{kg}^{-1}\right)$ & \multicolumn{6}{|c|}{ 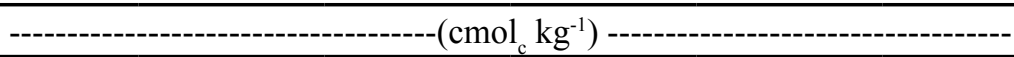 } \\
\hline 5,30 & 1,05 & 20,20 & 0,14 & 0,14 & 0,40 & 0,20 & 0,15 & 3,05 \\
\hline & $\begin{array}{c}\text { Densidade } \\
\left(\mathrm{kg} \mathrm{m}^{-3}\right)\end{array}$ & & \multicolumn{2}{|c|}{ Areia } & \multicolumn{2}{|c|}{ Silte } & \multicolumn{2}{|c|}{ Argila } \\
\hline & 1,53 & & \multicolumn{2}{|c|}{820} & \multicolumn{2}{|c|}{40} & \multicolumn{2}{|c|}{140} \\
\hline
\end{tabular}

\footnotetext{
* Na determinação do teor de fósforo utilizado o extrator químico Mehlich 1
} 
0,01 ou 0,05 de probabilidade, sendo apresentados os modelos polinomiais de melhor ajuste.

\section{Resultados e discussão}

A partir da análise de variância, foi verificado efeito significativo da salinidade (S), ao nível de significância de $1 \%$, para todas as características avaliadas. Para os níveis de fósforo $(\mathrm{P})$, foi encontrada diferença significativa para número de folhas (NF), ao nível de significância de 5\%, enquanto que, para área foliar (AF), Massa fresca (MFR) e seca da raiz (MSR), verificou-se efeito significativo a $1 \%$ probabilidade. Com relação à interação $\mathrm{S} x \mathrm{P}$, foi encontrado efeito significativo para AF e MFR $(\mathrm{p}<0,01)$ e MSR $(\mathrm{p}<$ $0,05)$, não sendo encontrada resposta significativa para NF $(\mathrm{p}>0,05)$, conforme mostrado na Tabela 2.

O desenvolvimento da raiz e da parte aérea são as características mais importantes para avaliação das plantas em estresse salino, uma vez que as raízes estão em contato direto com o meio salino, assim, essas características fornecem informações importantes sobre a resposta das plantas às condições de estresse (JAMIL; RHA, 2004).

$\mathrm{O}$ número de folhas (NF) foi reduzido com o incremento da salinidade da água da irrigação, no entanto, só foi encontrada diferença significativa a partir do nível salino de $3,5 \mathrm{dS} \mathrm{m}^{-1}$. O maior $\mathrm{NF}$ foi observado nas plantas irrigadas com água de menor salinidade $\left(0,5 \mathrm{dS} \mathrm{m} \mathrm{m}^{-1}\right)$, obtendo-se 6,9 folhas por planta, enquanto que, nas maiores salinidades (de 3,5 e 5,0 $\mathrm{dS} \mathrm{m}^{-1}$ ), foram observados os menores valores, 5,5 e 3,6 folhas por planta, correspondentes a reduções de 19,7 e 47,6\%, respectivamente. Apesar da redução do número de folhas com o aumento da salinidade, a equação de melhor ajuste foi a do tipo quadrática, com elevado coeficiente de determinação $\left(R^{2}=0,99\right.$; FIG.1A).

Tabela 2 - Resumo da análise de variância para número de folhas (NF), área foliar (AF), Massa fresca da raiz (MFR) e Massa seca da raiz (MSR) de rabanete sob diferentes níveis de salinidade da água de irrigação e doses de fósforo

\begin{tabular}{cccccc}
\hline \multirow{2}{*}{ Fontes de variação } & \multirow{2}{*}{ GL } & \multicolumn{1}{c}{ NF } & AF & MFR & MSR \\
\cline { 3 - 5 } & & $27,25^{* *}$ & $222096,58^{* *}$ & $491,14^{* *}$ & $8,91^{* *}$ \\
\hline Salinidade (S) & 3 & $4,03^{*}$ & $93971,58^{* *}$ & $204,47^{* *}$ & $1,52^{* *}$ \\
Fósforo (P) & 3 & $1,19^{\text {ns }}$ & $30536,72^{* *}$ & $38,94^{* *}$ & $0,37^{*}$ \\
S x P & 9 & 1,29 & 6231,36 & 12,21 & 0,17 \\
Erro & 32 & 19,91 & 23,64 & 17,09 & 22,02 \\
\hline CV (\%) & &
\end{tabular}

$*, * * \mathrm{e}^{\mathrm{ns}}$ - Significativo a $1 \%, 5 \%$ e não significativo, respectivamente
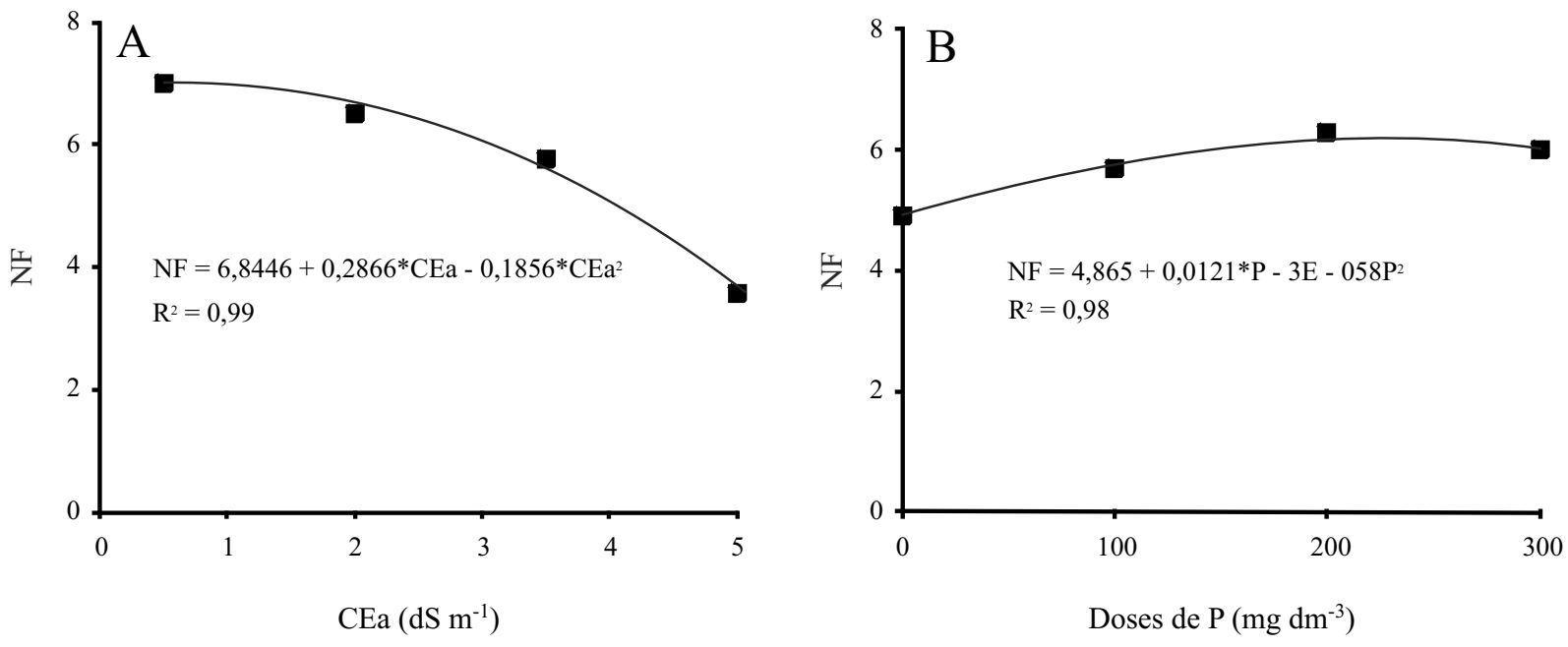

Figura 1 - Número de folhas de rabanete em função de níveis de salinidade da água da irrigação (1A) e doses de fósforo (1B) 
Yildrim et al. (2008), avaliando o desenvolvimento do rabanete em duas condições de salinidade $(1,86 \mathrm{e}$ $12,14 \mathrm{dS} \mathrm{m}^{-1}$ ), observaram cerca de 6,5 folhas por planta no meio menos salino, e que no meio mais salino houve redução no NF em cerca de $38 \%$. Redução no número de folhas, em resposta à salinidade, também foram encontrados para outras culturas, como rúcula (SILVA et al., 2008), milho pipoca (OLIVEIRA et al., 2009), entre outras culturas de valor agronômico.

Para os níveis de fósforo $(\mathrm{P})$, foi verificado efeito significativo e positivo no NF com incremento do nível de $\mathrm{P}$ até um determinado nível $\left(202 \mathrm{mg} \mathrm{dm}{ }^{3}\right)$, sendo a partir deste nível observado uma resposta decrescente. A equação de melhor ajuste foi a do tipo quadrática, com coeficiente de determinação $\left(\mathrm{R}^{2}\right)$ de 0,98 . O máximo $\mathrm{NF}$ foi obtido com a dose de $202 \mathrm{mg} \mathrm{dm}^{3}$, obtendo-se 6,1 folhas por planta, resultando num incremento em cerca de $25,1 \%$ em relação ao tratamento sem aplicação de fósforo $\left(\mathrm{P}_{1}\right)$, onde foi observado 4,9 folhas por planta. (FIG. 1B).

A área foliar (AF) foi afetada pela interação entre os fatores salinidade S x P. Assim, a resposta do rabanete a estes fatores foi avaliada para cada fator isoladamente. Avaliando o efeito da salinidade em cada dose de P, podese verificar que, na salinidade testemunha $\left(\mathrm{S}_{1}\right)$, os maiores valores foram obtidos no nível de fósforo $\mathrm{P}_{3}\left(658,3 \mathrm{~cm}^{2}\right.$ planta $\left.^{-1}\right)$. Para $\mathrm{P}_{1}, \mathrm{P}_{3}$ e $\mathrm{P}_{4}$, as equações que apresentaram melhor ajuste foram do tipo linear, com redução na área foliar em cerca de $76,7 \%, 64,5 \%$ e $59,4 \%$, respectivamente, no nível salino $\mathrm{S}_{4}\left(5,0 \mathrm{dS} \mathrm{m}^{-1}\right)$, em relação ao menor nível salino $\mathrm{S}_{1}\left(0,5 \mathrm{dS} \mathrm{m}^{-1}\right)$. Para o nível $\mathrm{P}_{2}$ foi obtida resposta quadrática $\left(\mathrm{R}^{2}>0,98\right)$, sendo observada acréscimo na $A F$ até uma determinada salinidade da água de irrigação (1,98 dS m $\mathrm{d}^{-1}$, com AF estimada em 393,7 $\mathrm{cm}^{2}$ planta $^{-1}$, resultando num incremento de $18,0 \%$,em relação a $\mathrm{AF}$ obtida em $\mathrm{S}_{1}$ (FIG. 2A). Jamil et al. (2007) verificaram redução na área foliar do rabanete com salinidade acima de 4,7 $\mathrm{dS} \mathrm{m} \mathrm{m}^{-1}$, quando observaram maiores valores para AF em torno de $45 \mathrm{~cm}^{2}$ planta-1. No entanto, esses autores fizeram as avaliações biométricas quando as plantas apresentavam 15 dias após a germinação.

Resposta negativa da cultura do rabanete à salinidade também foi encontrada por Marcelis e Hooijdonk (1999), que avaliaram o desenvolvimento da cultura do rabanete, em diferentes níveis salinos $(1 ; 2 ; 4$; 9 e $\left.13 \mathrm{dS} \mathrm{m}^{-1}\right)$, e verificaram o máximo desenvolvimento das plantas com salinidade do solo na faixa de 2 a $4 \mathrm{dS} \mathrm{m}^{-1}$, com significativas reduções da área foliar e no acúmulo de fitomassa da parte aérea e das raízes. A maior tolerância da cultura do rabanete, observada por esses autores, pode ter sido devida a composição da solução utilizada, pois os diferentes níveis salinos foram obtidos pela adição de diferentes fertilizantes, resultando, assim, em maior concentração de nutrientes disponíveis para as plantas.

Sabe-se que, em condições adversas, as plantas desenvolvem formas de adaptação, resultando em alterações bioquímicas elou morfológicas. Segundo Tester e Davenport (2003), o decréscimo da área foliar, possivelmente, está relacionado com um dos mecanismos de adaptação da planta ao estresse salino, diminuindo a superfície transpirante.

De acordo com Marcelis e Hooijdonk (1999), cerca de $80 \%$ da redução de crescimento do rabanete, provocado pela salinidade, pode ser atribuída à redução da expansão foliar e, consequentemente, na redução da interceptação da luz, enquanto que os outros $20 \%$ restantes pode ser explicada pela diminuição na condutância estomática.
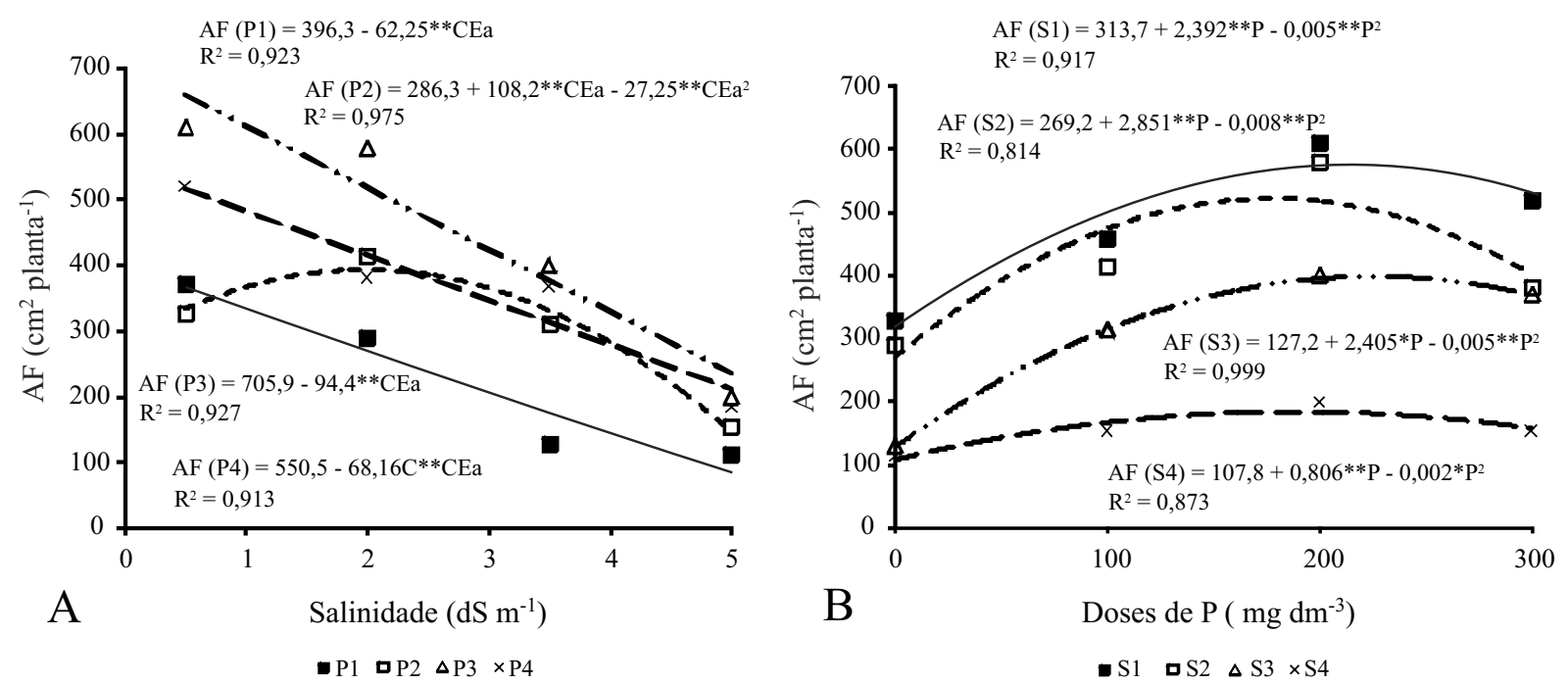

Figura 2 - Área foliar de rabanete em função de níveis de salinidade da água da irrigação (2A) e doses de fósforo (2B) 
Para todos os níveis salinos (S), a cultura respondeu as doses de fósforo, sendo ajustada equação quadrática para ambos, com equações apresentando satisfatório coeficiente de determinação $\left(\mathrm{R}^{2}>0,80\right)$. Analisando o efeito das doses de $\mathrm{P}$ em cada nível de salinidade S (FIG. 2B), pode-se verificar que a resposta da cultura foi variada de acordo com a salinidade. As equações ajustadas foram derivadas. Desta forma, foram determinadas as doses que proporcionaram o maior desenvolvimento foliar, sendo estimadas as doses de $\mathrm{P}$ equivalentes a 239; 178; 240 e $202 \mathrm{mg} \mathrm{dm}^{-3}$, para os níveis crescentes de salinidade $\left(\mathrm{S}_{1}, \mathrm{~S}_{2}, \mathrm{~S}_{3}\right.$ e $\left.\mathrm{S}_{4}\right)$, sendo estimada AF de 600; $523 ; 415$ e $222 \mathrm{~cm}^{2}$ planta $^{-1}$.

Comparando os valores de $\mathrm{AF}$, estimados com os obtidos na ausência da adubação fosfatada (FIG. 2B), verifica-se um incremento na $\mathrm{AF}$ em 83,4\%, 80,8\%, $223,65 \%$ e $268,4 \%$, nas salinidades $S_{1}, S_{2}, S_{3}$ e $S_{4}$, respectivamente.

A massa fresca das raízes (MFR) foi afetada significativamente pela interação $\mathrm{S}$ x $\mathrm{P}(\mathrm{p}<0,01)$, desta forma, foram avaliados o efeito da $\mathrm{S}$, dentro de cada nível de $\mathrm{P}$, e o efeito de $\mathrm{P}$, avaliado em cada nível de $\mathrm{S}$. As maiores MFR foram obtidas nas plantas que receberam adubação fosfatada, sendo estimada a MFR de 19,1 g planta $^{-1}$ para $P_{1}$, e de 32,5, 27,96 e 28,5 g planta $^{-1}$, para $\mathrm{P}_{2}$, $\mathrm{P}_{2}$ e $\mathrm{P}_{3}$, respectivamente. $\mathrm{O}$ aumento da salinidade afetou linearmente a MFR nos níveis $\mathrm{P}_{1}, \mathrm{P}_{2}$ e $\mathrm{P}_{4}$, com redução de $52,2 \%, 49,8 \%$ e $58,8 \%$, respectivamente, no maior nível salino $\left(5,0 \mathrm{dS} \mathrm{m}^{-1}\right)$, em comparação com os valores obtidos na menor salinidade $\left(0,5 \mathrm{dS} \mathrm{m} \mathrm{m}^{-1}\right)$. Para $\mathrm{P}_{3}$, verificou-se um incremento na MFR com aumento da salinidade até
$1,1 \mathrm{dS} \mathrm{m}^{-1}$, sendo observado efeito negativo a partir desta salinidade, com redução de 56,6\% nas plantas irrigadas com água de salinidade $\mathrm{S}_{4}$ em relação a $\mathrm{S}_{1}$ (FIG. 3A).

Analisando o efeito das doses de $\mathrm{P}$ em cada S (FIG. 3B), pode-se verificar que nas salinidades $S_{1}, S_{2}$ e $S_{3}$ as plantas responderam de forma quadrática. As máximas MFR foram estimadas nas doses de $\mathrm{P}$ equivalentes a 194; 170; $199 \mathrm{mg} \mathrm{dm}^{-3}$, para $\mathrm{S}_{1}, \mathrm{~S}_{2}$ e $\mathrm{S}_{3}$, respectivamente. Sendo estimadas MFR de 30; 32 e 22 g planta $^{-1}$, para $\mathrm{P}_{2}$, $\mathrm{P}_{3}$ e $\mathrm{P}_{4}$, respectivamente, proporcionando um incremento de $60 \% ; 104 \%$ e $165 \%$, em relação a $P_{1}$. Esses resultados evidenciam que a adubação fosfatada, até certo nível, reduziu a sensibilidade da cultura do rabanete à salinidade. Para salinidade $\mathrm{S}_{4}$ foi encontrada resposta linear com decréscimo da MFR, por aumento nas doses de $\mathrm{P}$, estimando-se redução de $0,01 \mathrm{~g}$ planta por $\mathrm{mg} \mathrm{dm}^{-1}$ de $\mathrm{P}$ acrescentado no meio de cultivo.

Amassasecadasraízes foiafetadasignificativamente $(\mathrm{p}<0,01)$ pela salinidade da água utilizada na irrigação em todas as doses de fósforo, sendo reduzida linearmente de acordo com o aumento dos níveis salinos, no entanto, a intensidade desse afeito foi variada para cada nível de P (FIG. 4A). Para as plantas cultivadas sem adubação fosfatada $\left(\mathrm{P}_{1}\right)$, foi observada a maior redução da MSR $(81,6 \%)$ na salinidade $S_{4}$ em relação a $S_{1}$, enquanto que, nos demais níveis de $\mathrm{P}$, foram observados reduções de $72,0 \% ; 55,4 \%$ e $41,7 \%$, para $\mathrm{P}_{2}, \mathrm{P}_{3}$ e $\mathrm{P}_{4}$, respectivamente. Resultados semelhantes foram obtidos por Yildrim et al. (2008), que avaliaram o desenvolvimento do rabanete em solo salino e verificaram significativa redução na massa seca das raízes.
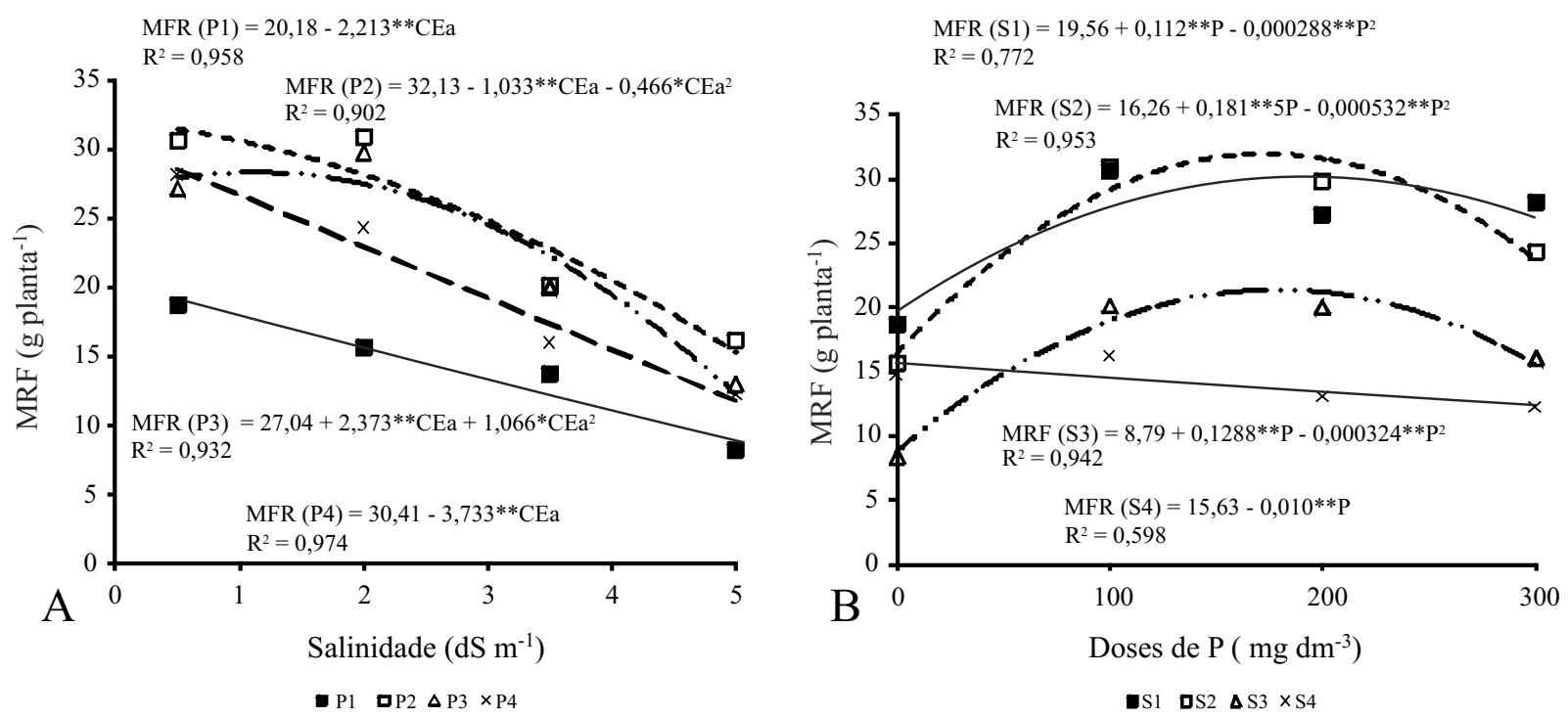

Figura 3 - Massa fresca das raízes de rabanete em função de níveis de salinidade da água da irrigação (3A) e doses de fósforo (3B) 

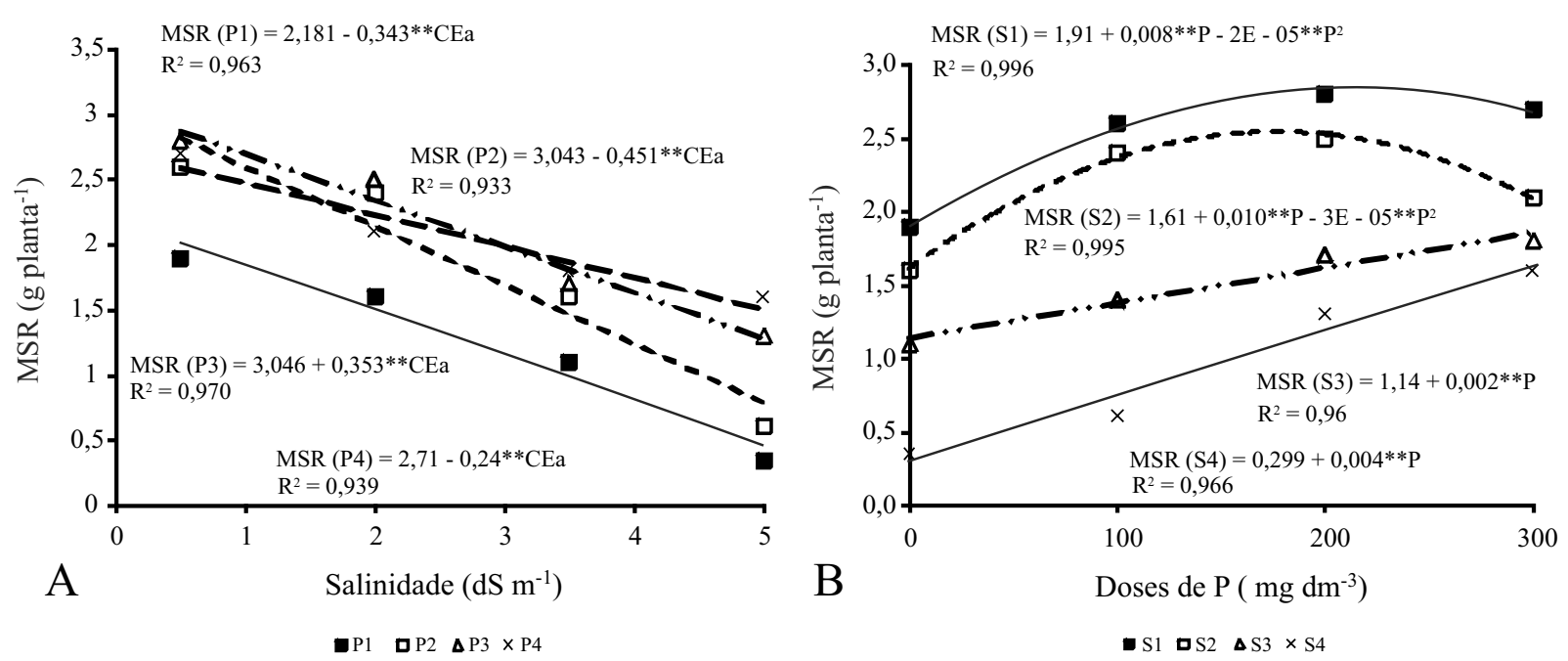

Figura 4 - Massa seca das raízes de rabanete em função de níveis de salinidade da água da irrigação (4A) e doses de fósforo (4B)

Avaliando o efeito da adubação fosfatada em cada nível de salinidade (FIG. 4B), a resposta da cultura foi influenciada significativamente $(\mathrm{p}<0,01)$ em cada salinidade. Para as salinidades $\mathrm{S}_{1}$ e $\mathrm{S}_{2}$, foi verificada resposta quadrática ao incremento nos níveis de P. Os maiores valores de MSR foram estimados para as doses de $200 \mathrm{mg} \mathrm{dm}^{-3}\left(\mathrm{~S}_{1}\right)$ e $167 \mathrm{mg} \mathrm{dm}^{-3}\left(\mathrm{~S}_{2}\right)$, correspondente ao um incremento de $42,1 \%$ e $52,7 \%$ nas salinidades $\mathrm{S}_{1}$ e $\mathrm{S}_{2}$, respectivamente, em relação a $\mathrm{P}_{1}$. Para as salinidades $\mathrm{S}_{3}$ e $\mathrm{S}_{4}$, foi observada resposta linear e crescente, de acordo com o incremento da adubação fosfatada, sendo estimado aumento da MSR em $52,6 \%$ e $401,3 \%$, respectivamente. O maior valor de MSR encontrado neste trabalho (3,5 g planta $^{-1}$ ) foi obtido na dose de $200 \mathrm{mg} \mathrm{dm}^{-3} \mathrm{de} \mathrm{P}$, irrigado com água de salinidade $\mathrm{S}_{1}$.

Apesar serem observadas reduções significativas no desenvolvimento da parte aérea e das raízes de rabanete em todos os níveis de $\mathrm{P}$, percebe-se que as plantas que receberam fertilização fosfatada foram menos afetadas que aquelas cultivadas sem adubação fosfatada, demonstrando, assim, que, mesmo em condições onde o uso de água salina seja inevitável, a adubação fosfatada permite o cultivo da cultura do rabanete, com satisfatório desenvolvimento de raízes.

Os resultados obtidos neste trabalho evidenciam que a cultura do rabanete responde a adubação fosfatada, sendo a resposta mais expressiva nas condições de maior estresse salino. Bacarin et al. (2007) e Jamil et al. (2007) estudaram o efeito da salinidade sobre o desenvolvimento do rabanete cultivado em solução nutritiva e verificaram redução na área foliar, massa seca da parte aérea e de raízes do rabanete em resposta à salinidade.
Segundo Flowers (2004), em condições de estresse salino, as plantas fecham os estômatos para reduzir a transpiração, tendo como conseqüência uma redução da taxa fotossintética, podendo esta alteração morfofisiológica ser uma das principais causas na diminuição do crescimento das espécies nestas condições. Outra causa possível para redução dos parâmetros de desenvolvimento vegetal observado neste trabalho, pode estar relacionado a um possível desbalanço nutricional das plantas provocado pelas maiores salinidades (TAIZ; ZEIGER, 2004), conforme observado por Abdelrahman (1987) e Yildrim et al. (2008) para cultura do rabanete. Alguns autores também constataram desbalanço nutricional em virtude da salinidade para outras culturas, como berinjela (BOSCO et al., 2009) e meloeiro (MEDEIROS et al., 2008), entre outras culturas de interesse agronômico.

\section{Conclusão}

1. As plantas foram afetadas pela salinidade da água de irrigação, com efeitos mais severos maiores para área foliar e massa seca das raízes;

2. A qualidade da água de irrigação é fator fundamental na determinação da adubação fosfatada, com resposta mais eficiente em irrigações com águas de baixa salinidade;

3. A cultura do rabanete respondeu significativamente a interação entre salinidade e fósforo para área foliar, massa fresca e massa seca das raízes; e de forma isolada para número de folhas;

4. Doses crescentes de fósforo reduziram à sensibilidade da cultura do rabanete irrigado com água de salinidade até $3,5 \mathrm{dS} \mathrm{m}^{-1}$; 
5. O manejo da adubação fosfatada é uma alternativa para amenizar o efeito da salinidade no desenvolvimento da cultura do rabanete.

\section{Referências}

ABDELRAHMAN, A. M. Effects of salinity and gibberellin on water-content, growth and mineral -composition of cowpea, calabrese and red radish plants.Biologia Plantarum, v. 29, n. 05, p. $365-373,1987$.

ASSIS JUNIOR, J. O. et al. Produtividade do feijão-de-corda e acúmulo de sais no solo em função da fração de lixiviação e da salinidade da água de irrigação. Engenharia Agrícola, v. 27, n. 03 , p. $702-713,2007$.

BACARIN, M. A. et al. Crescimento e fotossíntese em plantas de rabanete sob estresse salino. Revista Brasileira de Agrociência, v. 13, n. 04, p. 473-479, 2007.

BOSCO, M. R. O. et al. Influência do estresse salino na composição mineral da berinjela. Revista Ciência Agronômica, v. 40, n. 02 , p. $157-164,2009$.

CERDA, A. et al. Interactive Effect of Salinity and Phosphorus on Sesame. Soil Science Society of America Journal. v. 41, p. 915-918, 1977.

EMPRESABRASILEIRADEPESQUISA AGROPECUÁRIA (EMBRAPA). Manual de métodos de análises de solo. 2. ed. Rio de Janeiro: Ministério da Agricultura e do Abastecimento, 1997. $212 \mathrm{p}$

FILGUEIRA, F. A. R. Novo manual de olericultura: Agrotecnologia moderna na produção e comercialização de hortaliças. Viçosa-MG: UFV, 2008. 421 p.

FLOWERS, T. J. Improving crop salt tolerance. Journal of Experimental Botany, v. 55, n. 396, p. 307-319, 2004.

GRATTAN, S. R.; GRIEVE, C. M. Salinity-mineral nutrient relations in horticultural crops. Scientia Horticulturae, v. 78, n. 01/04, p. 127-157, 1999.

JAMIL, M. et al. Salinity reduced growth PS2 photochemistry and chlorophyll content in radish. Scientia Agricola, v. 64, n. 02, p. 111-118, 2007.

JAMIL, M.; RHA, E. S. The effect of salinity $(\mathrm{NaCl})$ on the germination and seedling of sugar beet (Beta vulgaris L.) and cabbage (Brassica oleracea capitata L.). Korean Journal of Plant Resources, v. 07, p. 226-232, 2004.
LACERDA, C. F. et al. Interação entre salinidade e fósforo em plantas de sorgo forrageiro. Revista Ciência Agronômica, v. 37 , n. 02 , p. $258-263,2006$.

OLIVEIRA, M.; MAIA, C. E. Qualidade fisico-química da água para irrigação em diferentes aquíferos na área sedimentar do estado do rio grande do norte. Revista Brasileira de Engenharia Agrícola e Ambiental, v.2, p.17-21, 1998.

MARSCHENER, H. Mineral nutrition of higher plants. San Diego: Academic Press, 2002. 889p.

MAAS, E. V.; HOFFMAN, G. J. Crop salt tolerance - Current assessment. Journal of Irrigation and Drainage Division, v.103, n.Ir², p.115-134, 1977.

MARCELIS, L. F. M.; HOOIJDONK, J. V. Effect of salinity on growth, water use and nutrient use in radish (Raphanus sativus L.). Plant and Soil, v. 215, p. 57-64, 1999.

MEDEIROS, J. F. et al. Caracterização das águas subterrâneas usadas para irrigação na área produtora de melão da Chapada do Apodi. Revista Brasileira de Engenharia Agrícola e Ambiental, v. 07, n. 03, p. 469-472, 2003.

MEDEIROS, J. F. et al. Crescimento e acúmulo de N, P e $\mathrm{K}$ pelo meloeiro irrigado com água salina. Horticultura Brasileira, v. 26, n. 04, p. 452-457, 2008.

MINAMI, K.; NETTO, J. T. Rabanete: cultura rápida, para temperaturas amenas e solos areno-argilosos. Piracicaba: ESALQ, 1997. 27 p. (Série Produtor Rural, 4).

NARLOCH, C. et al. Resposta da cultura do rabanete à inoculação de fungos solubilizadores de fosfatos. Pesquisa Agropecuária Brasileira, v. 37, n. 06, p. 841-845, 2002.

OLIVEIRA, F. A. et al. Desenvolvimento inicial do milho pipoca irrigado com água de diferente níveis de salinidade. Revista Brasileira de Ciências Agrárias, v. 04, n. 02, p. 149-155, 2009.

SHIBLI, R. A. et al. Increased phosphorus mitigates the adverse effects of salinity in tissue culture. Communications in Soil Science and Plant Analysis, v. 32, n. 03/04, p. 429-440, 2001.

SILVA, J. K. M. et al. Efeito da salinidade e adubos orgânicos no desenvolvimento da rúcula. Caatinga, v. 21, n. 05, p. 30-35, 2008.

TAIZ, L.; ZEIGER, E. Fisiologia vegetal. 3. ed. Porto Alegre: Artmed. 2004. 719 p

TESTER, M.; DAVENPORT, R. Na ${ }^{+}$tolerance and $\mathrm{Na}^{+}$transport in higher plants. Annals of Botany, v. 91, p. 503-527, 2003.

YILDRIM, E. et al. Use of bioinoculants in ameliorative effects on radish plants under salinity stress. Journal of Plant Nutrition. v. 31, n. 12, p. 2059-2074, 2008. 